\title{
Central haemodynamics during spontaneous angina pectoris
}

\author{
Harry Lecerof \\ From the Department of Clinical Physiology, Malmö General Hospital, S-214 or Malmö, Sweden.
}

Central pressures and flows observed in 5 patients during spontaneous angina pectoris indicated left ventricular failure. Before the attack there was already a tendency towards increased left ventricular filling pressure. After nitroglycerin both pulmonary and brachial artery pressures fell. During spontaneous angina pectoris, pulmonary and brachial artery pressures were at least as high as during angina of effort in another group of patients, but heart rate and stroke volume were lower.

Systematic haemodynamic investigations of spontaneously occurring angina pectoris have for obvious reasons been difficult to perform. The first description of increased heart rate and raised blood pressure during spontaneous angina is, however, more than Ioo years old (Brunton, 1867). In 1966 a critical review of circulatory changes during an acute attack of angina pectoris was published, a review that also contained descriptions of 30 cases of spontaneously occurring angina pectoris (Roughgarden and Newman, 1966). In a separate study original observations in 13 patients with spontaneous angina pectoris were reported (Roughgarden, I966). These observations included systemic blood pressure and electrocardiograms before, during, and after the attack of anginal pain, and in 6 patients simultaneous recordings of the pulmonary arterial or right ventricular pressure were performed. Cardiac output determination was not made in Roughgarden's study and recordings of cardiac output and stroke volume in connexion with spontaneous angina pectoris have only been reported in single cases (Gorlin, 1965; Rosland, 1969). The present study describes central pressures and flows in patients with spontaneous angina pectoris and relates these findings to observations made during effort angina and also to observations made at rest in a larger series of patients with angina pectoris previously reported in part (Malmborg, Arborelius, and Lecerof, 1972).

\section{Subjects and methods}

Between 1964 and 1972,87 male patients all with typical angina pectoris have been studied with right heart Received 20 February 1974 .
TABLE I Pertinent clinical data

\begin{tabular}{lllll}
\hline $\begin{array}{l}\text { Case } \\
\text { no. }\end{array}$ & $\begin{array}{l}\text { Age } \\
(y r)\end{array}$ & $\begin{array}{l}\text { Functional } \\
\text { class } N Y H A \\
I-I V\end{array}$ & $\begin{array}{l}\text { Heart volume } \\
\left(\mathrm{ml} / \mathrm{m}^{2}\right)\end{array}$ & $\begin{array}{l}\text { Number of } \\
\text { myocardial } \\
\text { infarctions }\end{array}$ \\
\hline I & 47 & III & 390 & I \\
2 & 62 & III & 470 & I \\
3 & 62 & III & 530 & I \\
4 & 7 I & III & 600 & 2 \\
5 & 50 & III & 640 & I \\
6 & 4 II & IV & 480 & 1 \\
7 & 64 & III & 530 & I \\
\hline
\end{tabular}

catheterization as part of a thorough evaluation of their cardiac function before operation aimed at improving their myocardial blood supply (group I A, Table 3). In 71 patients measurements have been obtained during angina pectoris precipitated by exercise (group I B, Table 3). Of the remainder, 9 patients developed angina pectoris without being subjected to external physical stress. In 2 of these patients, however, no measurements were recorded during angina. Thus, measurements during spontaneous angina pectoris were obtained in 7 men between $4 \mathrm{I}$ and 64 years of age, all with typical clinical and electrocardiographic signs of coronary heart disease (group 2, Table 3). Pertinent clinical data are given in Table I. Coronary arteriography showed triple vessel disease in 5 patients (Cases $1,3,5,6$, and 7) and double vessel disease in one (Case 2). In one patient (Case 4) coronary arteriography was not performed because of raised plasma creatinine. The subjects were not anaemic and none of them had signs of congestive heart failure or rheumatic heart disease. All were in sinus rhythm at the time of the study. The investigations were performed in the morning when the patients were in the postabsorptive basal state. Right heart catheterization was performed with a double lumen catheter and 
TABLE 2 Individual haemodynamic data when free of symptoms (FOS), during spontaneous angina pectoris $(S A P)$ and after $0.5 \mathrm{mg}$ nitroglycerin sublingually $(A N)$

\begin{tabular}{|c|c|c|c|c|c|c|c|}
\hline Case No. & $\begin{array}{l}\text { Heart rate } \\
\text { (beats/min) }\end{array}$ & $\begin{array}{l}\text { Stroke } \\
\text { volume } \\
\text { (ml) }\end{array}$ & $\begin{array}{l}\text { Cardiac } \\
\text { output } \\
\text { (l./min) }\end{array}$ & $\begin{array}{l}\text { Arterio- } \\
\text { venous } \\
\mathrm{O}_{2} \text {-diff. } \\
(\mathrm{ml} / \mathrm{l} .)\end{array}$ & $\begin{array}{l}\text { Pulmo } \\
\text { pressu } \\
\text { Syst. }\end{array}$ & $\begin{array}{l}\text { arterial } \\
\text { MHg) } \\
\text { Mean }\end{array}$ & Diast \\
\hline (FOS & 76 & 99 & 7.5 & 40 & 29 & 21 & 12 \\
\hline I SAP & 76 & 96 & $7 \cdot 3$ & 44 & 49 & 35 & 30 \\
\hline AN & 84 & 84 & $7 \cdot 0$ & - & 22 & 10 & 7 \\
\hline (FOS & 82 & 69 & $5 \cdot 6$ & 53 & 28 & 15 & Io \\
\hline $2\{$ SAP & 98 & 48 & 4.7 & - & 83 & 60 & 38 \\
\hline AN & 74 & - & - & - & 30 & 18 & 9 \\
\hline FOS & 54 & 77 & $4 \cdot 2$ & - & 28 & 20 & 14 \\
\hline 3 SAP & 64 & 78 & 5.0 & - & 40 & 30 & 22 \\
\hline AN & 60 & - & - & - & 33 & 22 & 14 \\
\hline $\int$ FOS & 74 & - & - & - & 42 & 32 & 23 \\
\hline 4 SAP & 96 & 39 & 3.7 & 58 & 60 & 54 & 37 \\
\hline FOS & 82 & - & - & - & 27 & 15 & 13 \\
\hline 5 SAP & 99 & 52 & $5 \cdot 2$ & 43 & 52 & 41 & 32 \\
\hline (FOS & 67 & - & - & - & 30 & 21 & 16 \\
\hline $6\{$ SAP & 74 & - & - & 49 & 33 & - & 19 \\
\hline AN & 76 & - & - & - & 27 & 20 & 14 \\
\hline 7 SAP & 76 & - & - & 一 & 40 & 29 & 23 \\
\hline
\end{tabular}

TABLE 3 Mean haemodynamic data \pm I standard deviation $(S D)$ with statistical significance $(P)$ of the differences between means

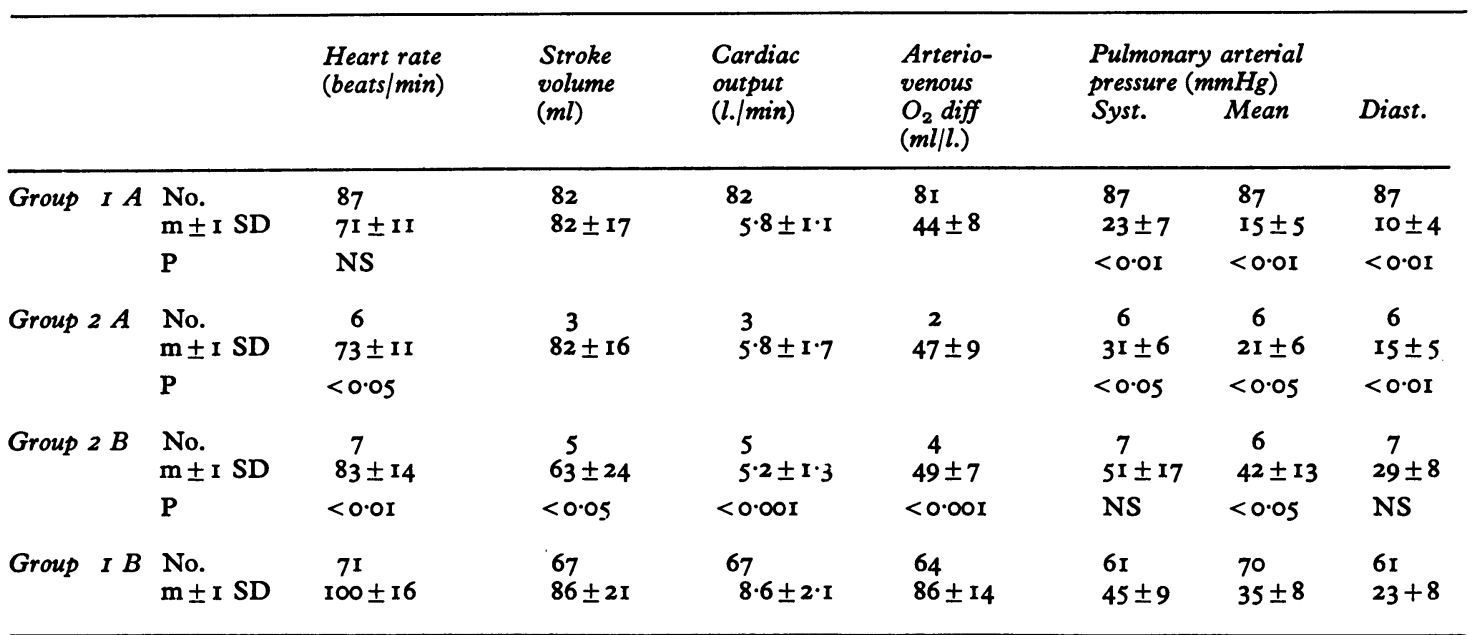

Note: Group I = patients with effort angina studied at rest (I A) and during exercise precipitating angina pectoris (I B). Group $2=$ patients with spontaneous angina studied when free of symptoms ( $2 \mathrm{~A})$ and during spontaneous angina pectoris (2 B).

the brachial artery was catheterized percutaneously. Cardiac output was determined according to the Fick principle and also by the indicator dilution technique using bromsulphalein (Wassén, 1956). Inductance manometers and a four-channel Mingograph (Siemens Elema $A B$, Stockholm, Sweden) were used for registration and recording of pressures. Systemic vascular resistance was calculated according to the following formula:

Systemic vascular resistance $($ SVR $)=\overline{\mathbf{P}}_{\mathrm{BA}} / \dot{\mathrm{Q}}$ where $\dot{\mathbf{Q}}=$ cardiac output and $\overline{\mathbf{P}}_{\mathrm{BA}}=$ mean brachial arterial pressure. The patients were studied in the supine position. Five patients developed angina pectoris during sampling of expired air for cardiac output determination and one after raising his legs in preparation for supine bicycle exercise. In Cases I to 6 measurements were obtained at rest when the patients were free of pain as well as during spontaneous angina pectoris. In 4 patients measurements were obtained 


\begin{tabular}{|c|c|c|c|c|}
\hline \multirow{2}{*}{$\begin{array}{l}\text { Pulm. capillary } \\
\text { venous pressure } \\
\text { (mmHg) } \\
\text { Mean }\end{array}$} & \multicolumn{2}{|c|}{$\begin{array}{l}\text { Systemic arterial } \\
\text { pressure }(\mathrm{mmHg})\end{array}$} & \multirow[b]{2}{*}{ Diast. } & \multirow{2}{*}{$\begin{array}{l}\text { Systemic } \\
\text { vascular } \\
\text { resistance }\end{array}$} \\
\hline & Syst. & Mean & & \\
\hline I I & 152 & II 4 & 90 & $15 \cdot 2$ \\
\hline 23 & 200 & 150 & 115 & 20.5 \\
\hline 7 & 16I & 126 & 103 & $18 \cdot 0$ \\
\hline- & 175 & III & 89 & 19.8 \\
\hline - & 214 & 155 & 129 & $33 \cdot 0$ \\
\hline - & 151 & II2 & 81 & - \\
\hline 14 & I3I & 92 & 75 & $22 \cdot 0$ \\
\hline 23 & 161 & 118 & 103 & $23 \cdot 6$ \\
\hline 13 & 128 & - & 84 & - \\
\hline 22 & 131 & 9I & 76 & - \\
\hline 40 & 140 & 103 & 87 & $27 \cdot 8$ \\
\hline 9 & 129 & 87 & 81 & - \\
\hline 35 & 167 & 133 & 100 & $25 \cdot 6$ \\
\hline 6 & II3 & 87 & 67 & - \\
\hline 21 & 122 & - & 75 & - \\
\hline I2 & 109 & 88 & 68 & - \\
\hline 24 & 195 & I 45 & 122 & - \\
\hline
\end{tabular}

Pulm. capillary Systemic arterial venous pressure pressure $(\mathrm{mmHg})$ $(m m H g) \quad S y s t . \quad M e a n$ Mean

\begin{tabular}{cccll}
\hline 82 & 87 & 87 & 87 & 81 \\
$8 \pm 4$ & $146 \pm 25$ & $106 \pm 17$ & $80 \pm 16$ & $18 \cdot 7 \pm 4 \cdot 8$ \\
$<0.05$ & $N S$ & $N S$ & $N S$ & \\
5 & 6 & 6 & 6 & \\
$12 \pm 6$ & $139 \pm 22$ & $97 \pm 12$ & $80 \pm 9$ & $19 \cdot 0 \pm 3.5$ \\
$<0.01$ & $<0.01$ & $<0.01$ & $<0.01$ & \\
6 & & & & \\
$28 \pm 8$ & $171 \pm 34$ & $134 \pm 20$ & $104 \pm 19$ & $26 \cdot 1 \pm 4 \cdot 7$ \\
$N S$ & $N S$ & $N S$ & $N S$ & $<0.001$ \\
69 & 63 & 70 & 63 & 66 \\
$26 \pm 9$ & $169 \pm 25$ & $125 \pm 19$ & $94 \pm 17$ & $15 \cdot 3 \pm 4 \cdot 5$ \\
& & & & \\
\hline
\end{tabular}

after $0.5 \mathrm{mg}$ nitroglycerin given sublingually (Table 2) for relief of angina pectoris. In Table 3 Student's two sample t-test was used for comparisons of means.

\section{Results}

Individual data for patients in group 2 are given in Table 2. In Table 3 means and standard deviations of single parameters from these patients are pre- sented and compared with data from the larger series of patients with effort angina.

As is evident from Table 3, the patients with spontaneous angina pectoris when free of pain (group $2 \mathrm{~A}$ ) also differed from the larger group of patients with effort angina studied at rest (group I A). Thus, the pulmonary capillary venous and pulmonary artery pressure were definitely higher in group $2 \mathrm{~A}$, while the systemic arterial pressure tended to be lower.

A comparison within group 2 between observations made when free of symptoms and during spontaneous angina pectoris showed that angina was accompanied by increased heart rate and significantly higher pulmonary capillary venous and systemic arterial pressures (Tables 2 and 3). During spontaneous angina pectoris higher pressures were also observed in the pulmonary artery. The systemic vascular resistance seemed to increase during spontaneous angina pectoris, but as for cardiac output, stroke volume, and arteriovenous oxygen difference the number of observations was too small to allow definite conclusions. In every case where observations were made after sublingual administration of nitroglycerin a pronounced reduction of the pressures was noted in the systemic as well as in the lesser circulation (Table 2), findings that are in accordance with previous investigations (Müller and Rörvik, 1958; Arborelius et al., 1968).

Table 3 also presents a comparison of haemodynamic data during spontaneous angina pectoris with haemodynamic data during exercise-induced angina pectoris. During spontaneous angina pectoris heart rate was considerably lower. Cardiac output, stroke volume, and arteriovenous oxygen difference were also lower in spontaneous angina pectoris. However, during spontaneous angina pectoris the mean pulmonary arterial pressure was actually higher than during effort angina. The systemic vascular resistance was significantly higher during spontaneous angina pectoris and there was a tendency towards higher systemic blood pressure.

\section{Discussion}

At rest patients with effort angina do not generally exhibit signs of depressed left ventricular function (Müller and Rörvik, 1958; Sharma and Taylor, 1970). Malmborg (1965), however, observed a lower stroke volume and higher resistance in the systemic as well as in the lesser circulation in resting patients with angina on effort compared to normal subjects. From the present investigation it seems that also when free of symptoms patients suffering from spontaneous angina pectoris show higher pul- 
monary capillary venous pressure and pulmonary arterial pressure than observed at rest in a larger group of patients with effort angina (group I A, Table 3). These haemodynamic signs suggestive of abnormal left ventricular function might be secondary to the severe coronary atherosclerosis and loss of myocardium in the patients with spontaneous angina pectoris.

During spontaneous angina pectoris the systemic and pulmonary arterial pressures in the present investigation were almost identical to those described in a thoroughly investigated group of patients with spontaneous angina pectoris (Roughgarden, 1966). The percentage increase of heart rate from control (when free of symptoms) to spontaneous angina was also comparable ( 17 and $18 \%$, respectively). The rise in pulmonary capillary venous pressure during spontaneous angina pectoris observed in this study ( 9 to $26 \mathrm{mmHg}$ ) was similar to the rise in left ventricular end-diastolic pressure (12 to $25 \mathrm{mmHg}$ ) reported in patients with triple vessel disease by Amsterdam et al. (1969).

Recordings of cardiac output and stroke volume during spontaneous angina pectoris have been seldom reported. Müller and Rörvik (1958) assumed an increase of the cardiac output in 2 patients with spontaneous angina pectoris, an assumption that was based upon increased oxygen saturation in mixed venous blood. Gorlin (1965) reported one patient whose cardiac index fell from $2 \cdot 3$ to $1 \cdot 7$ during spontaneous angina pectoris. Serial determinations of cardiac output in one patient during spontaneous angina pectoris were published by Rosland (1969) and he also found a diminished cardiac output and stroke volume during spontaneous angina pectoris. In the present study variable changes in cardiac output and stroke volume were seen during spontaneous angina pectoris. However, no patient showed an increase in stroke volume during spontaneous angina pectoris in spite of increased filling pressure for the left ventricle.

Psychic stress and anxiety can at least partly explain the lability of the blood pressure found in many patients with spontaneous angina pectoris (Roughgarden, 1966). The intravascular pressures were also at least as high during spontaneous angina pectoris as during effort-induced angina (Table 3 ). Often spontaneous angina pectoris occurred during sampling of expired air for cardiac output determination, a situation that can be presumed to increase the sympathetic nervous tone. The anginal pain, when elicited, also tends to maintain a high degree of sympathetic tone. In this context it might be of interest to review briefly the chief determinants of myocardial oxygen consumption and to relate these determinants to the haemodynamic observations made in this study. The myocardial oxygen consumption is primarily dependent on the following factors (Braunwald, 1971): heart rate, contractile state of the muscle, preload, and afterload. Preload can be defined as the resting fibre length as determined by end-diastolic volume and is often expressed in terms of end-diastolic pressure (here substituted by $\overline{\mathrm{P}}_{\mathrm{PCV}}$ ). Afterload is the load that the ventricle must overcome during ejection; in the absence of aortic valve disease this is essentially a function of arterial pressure during diastole.

During spontaneous angina pectoris an increase in heart rate was found in Cases 2 to 6, while the heart rate remained unchanged in Case $I$. The contractility of the heart has not been studied here but is known to increase with increased sympathetic tone (Braunwald, Ross, and Sonnenblick, 1968). The pulmonary capillary venous pressure (corresponding to preload) increased in every case when measured before and during the anginal attack. In Case 2 a corresponding rise in the diastolic pulmonary arterial pressure was observed. The systolic arterial pressure (corresponding to afterload) also increased in all patients during spontaneous angina pectoris. Thus, irrespective of variations of single parameters the overall haemodynamic pattern in these patients points to an increase in the myocardial oxygen demand beyond a critical level where signs of abnormal left ventricular function were evident and angina pectoris was precipitated.

\section{References}

Amsterdam, E. A., Manchester, J. H., Kemp, H. G., and Gorlin, R. (1969). Spontaneous angina pectoris (SAP): hemodynamic and metabolic changes. Clinical Research, 17, 225.

Arborelius, M., Jr., Lecerof, H., Malm, A., and Malmborg, R. O. (1968). Acute effect of nitroglycerin on haemodynamics of angina pectoris. British Heart fournal, 30, 407 .

Braunwald, E. (1971). On the difference between the heart's output and its contractile state. Circulation, 43, I7I.

Braunwald, E., Ross, J., and Sonnenblick, E. H. (1968). Mechanisms of Contraction of the Normal and Failing Heart. Churchill, London.

Brunton, T. L. (1867). On the use of nitrite of amyl in angina pectoris. Lancet, 2, 97.

Gorlin, R. (1965). Pathophysiology of cardiac pain. Circulation, 32, 138.

Malmborg, R. O. (1965). A clinical and hemodynamic analysis of factors limiting the cardiac performance in patients with coronary heart disease. Acta Medica Scandinavica, 177, Suppl. 426.

Malmborg, R. O., Arborelius, M., Jr., and Lecerof, $\mathbf{H}$. (1972). Surgical treatment of angina pectoris. VI. Preand post-operative haemodynamic evaluations. Scandinavian fournal of Thoracic and Cardiovascular Surgery, 6, 87. 
Müller, O., and Rörvik, K. (1958). Haemodynamic consequences of coronary heart disease. With observations during anginal pain and on the effect of nitroglycerine. British Heart fournal, 20, 302.

Rosland, G. A. (1969). Haemodynamic observations during spontaneous angina pectoris. British Heart fournal, 3I, 523.

Roughgarden, J. W. (1966). Circulatory changes associated with spontaneous angina pectoris. American fournal of Medicine, 41, 947.

Roughgarden, J. W., and Newman :E. V. (1966). Circulatory changes during the pain of angina pectoris. 1772-1965 - A critical review. American fournal of Medicine, 41, 935.

Sharma, B., and Taylor, S. H. (1970). Reversible left-ventricular failure in angina pectoris. Lancet, 2, 902.

Wassén, A. (1956). The use of bromsulphalein for determination of the cardiac output. Scandinavian fournal of Clinical and Laboratory Investigation, 8, 189.

Requests for reprints to Dr. Harry Lecerof, Department of Clinical Physiology, Malmö General Hospital, S-2 I4 OI Malmö, Sweden. 